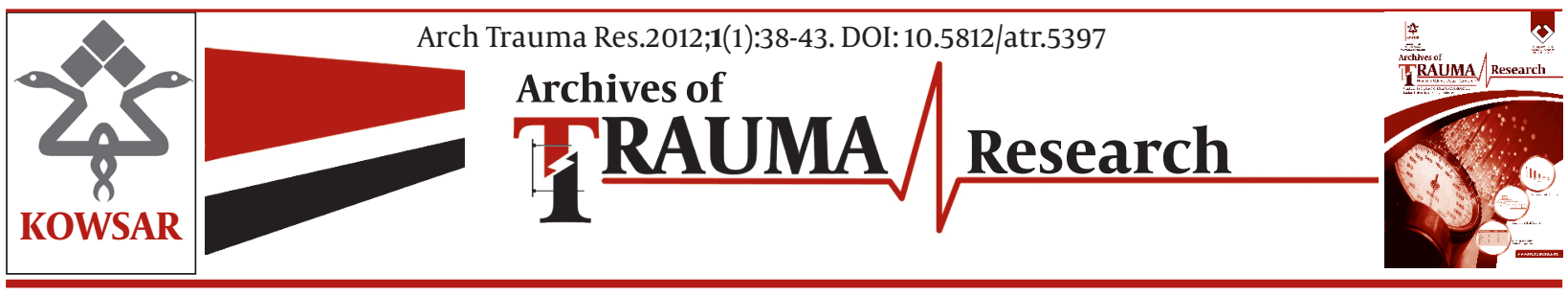

\title{
Effect of Gabapentin on Morphine Consumption and Pain after Surgical Debridement of Burn Wounds: A Double-Blind Randomized Clinical Trial Study
}

\author{
Siamak Rimaz ${ }^{1}$, Cyrus Emir Alavi ${ }^{{ }^{*}}$, Abbas Sedighinejad ${ }^{1}$, Mohammad Tolouie ${ }^{2}$, Sharareh \\ Kavoosi $^{3}$, Leila Kouchakinejad ${ }^{4}$ \\ ${ }^{1}$ Anesthesiology Research Center, Velayat University Hospital, Guilan University of Medical Sciences, Rasht, IR Iran \\ 2 Department of Burn Surgery, Velayat University Hospital, Guilan University of Medical Sciences, Rasht, IR Iran \\ ${ }^{3}$ Department of Guilan Country Planning, Rasht, IR Iran \\ ${ }^{4}$ Department of Nursing, Velayat University Hospital, Rasht, IR Iran
}

\begin{tabular}{l}
\hline A R T I C L E I N F O \\
\hline Article type: \\
Original Article \\
\hline Article history: \\
Received:14 Apr 2011 \\
Revised:17 Oct 2011 \\
Accepted: 20 Jan 2012 \\
\hline
\end{tabular}

Keywords:

Gabapentin

Morphine

Postoperative Pain

Surgery

\begin{abstract}
A B S T R A C T
Background: Burn pain is recognized as being maximal during therapeutic procedures, and wound debridement can be more painful than the burn injury itself. Uncontrolled acute burn pain increases the stress response and the incidence of chronic pain and associated depression. Although opiates are excellent analgesics, they do not effectively prevent central sensitization to pain. The anticonvulsant gabapentin has been proven effective for treating neuropathic pain in large placebo-controlled clinical trials. Experimental and clinical studies have demonstrated antihyperalgesic effects in models with central neuronal sensitization. It has been suggested that central neuronal sensitization may play an important role in postoperative pain.

Objectives: The aim of this study was to investigate the effect of gabapentin on morphine consumption and postoperative pain in burn patients undergoing resection of burn wounds.

Patients and Methods: In a randomized, double-blind, placebo-controlled study, 50 burn patients received a single oral dose of gabapentin (1200mg) or placebo $2 \mathrm{~h}$ before surgery. Anesthesia was induced with propofol and fentanyl and maintained by infusingpropofol, remifentanil, and 50\% $\mathrm{N} 2 \mathrm{O}$ in 02 . All patients received patient-controlled analgesia with morphine at doses of $2.5 \mathrm{mg}$ bolus and a lock-out time of $10 \mathrm{~min}$ for $24 \mathrm{~h}$ before the operation. Pain was assessed on a visual analog scale (VAS) at rest and during movement at 1,4,8,12,16,20, and $24 \mathrm{~h}$ before the operation. Heart rate, oxygen saturation, mean arterial blood pressure, respiratory rate, sedation score, and morphine consumption were studied.

Results: All the enrolled patients were able to complete the study; therefore, data from 50 patients wereanalyzed. The VAS scores at rest andduring movement at $1,4,8,12,16,20$, and $24 \mathrm{~h}$ after the operation were significantly lower in the gabapentin group than in the placebo group $(P<0.05)$. Morphine consumption was significantly lessr in the gabapentin group than in the placebo group $(P<0.05)$. Sedation scores were similar in the 2 groups at all measured times. There were no differences in adverse effects between the groups.

Conclusions: A single oral dose of $1200 \mathrm{mg}$ gabapentin resulted in a substantial reduction in postoperative morphine consumption and pain scores after surgical debridement in burn patients.
\end{abstract}

Copyright $\odot 2012$ Kowsar Corp

\footnotetext{
* Corresponding author: Cyrus Emir Alavi, Anesthesiology Research Center, Velayat University Hospital, Namjoo St., Rasht, Guilan Province, IR Iran. Tel: +98-9111317398, Fax:+98-1313245140, E-mail:cyrus.emiralavi@gmail.com

DOI:10.5812/atr.5397

Copyright $\odot 2012$ Kowsar Corp.
} 
Implication for health policy/practice/research/medical education:

Postoperative pain is a major challenge in burn patients. Opioids are less recommended for this purpose in burns due to its undesired side-effects, such as hyperalgesia, tolerance, addiction, pruritus and so on. This article is recommended to use oral Gabapentin to reduce postoperative morphine consumption and also pain scores after surgical debridement in burn patients.

- Please cite this paper as:

Rimaz S, Emir Alavi C, Sedighinejad A, Tolouie M, Kavosi S, Koochakinejad L. Effect of Gabapentin on Morphine Consumption and Pain after Surgical Debridement of Burn Wounds: A Double-Blind Randomized Clinical Trial Study. Arch Trauma Res. $2012 ; 1$ 1(1):38-43. DOI: 10.5812/atr.5397

\section{Background}

All burn injuries are painful, and burn patients commonly experience high levels of acute and excruciating pain during hospitalization. Pain is perceived at the time and site of the burn because of the stimulation of local nociceptors and transmission of nerve impulse in the $A \delta$ and $C$ fibers. These impulses relay the pain message to the dorsal horn of the spinal cord. Conscious perception of pain occurs as the impulse is transmitted onwards to the brain and into areas collectively known as the pain matrix (1). Compbell et al. (1984), indicated that the burn injury resulted inincreased sensitivity of Afibers, decreased sensitivity of $C$ fibers, increased pain sensitivity (hyperalgesia), and difficult-to-treat excessive pain (2). Some studies have suggested that burn patients have increased levels of anxiety, especially relating to treatment and outcome, and that these levels may increase overtime $(3,4)$. Burn pain is recognized as being maximal during therapeutic procedures (5), and wound debridement can be more painful than the burn injury itself (6).Uncontrolled acute burn pain increases the incidence of chronic pain and associated depression (7), and correlates with suicidal ideation at the time of discharge from hospital (8). Post-traumatic stress disorder is a notable sequelae of major burns and is linked, both as a cause and as an effect, with poorly controlled burn pain $(9,10)$. Avariety of pain measurement techniques have been used with adult burn patients. One of the most common measures is the numeric scale (i.e., rating pain on a scale of 0-100). This scale measures the sensory component of a patient's pain. The numeric scale is quick and easy to use because patients do not require a visual representation of the scale. To control background and procedural pain during the acute phase of burn treatment (72 $\mathrm{h}$ to 3 or 5 weeks, until the wounds are closed), the use of patient-controlled analgesia (PCA) is far superior to the PRN (from the Latin "Pro re nata" meaning"as needed") method (11). Furthermore, PCA has been described as safe and effective in both adults and children $(5,12,13)$. Of the agents recommended for the relief of acute pain, morphine has continued to be the mainstay for pain management. However, morphine binds to more than 1 receptor class, and morphine consumption is associated with side effects, such as respiratory depression, itching, nausea, vomiting, and constipation, that limit its use.An addi- tional problem is the rapid development of tolerance to morphine and poor pain control (11). Tolerance is defined as a requirement of increasing doses of a particular opioid to achieve the same analgesic effect and applies to side effects too (14). Tolerance to morphine is associated with the activation of the central glutamate pathways and hyperalgesia. Using other compounds such as gabapentin and ketamine, which block N-methyl-D-aspartate (NMDA) receptor pathways, improves the management of pain that can no longer be controlled with morphine (15). Because of the multiplicity of mechanisms involved in postoperative pain, a multimodal analgesia regimen, with a combination of opioid and non-opioid analgesic drugs, is often used to enhance analgesic efficacy and reduce opioid requirements and side effects (16). Gabapentin, a structural analog of gamma-aminobutyricacid, has antinociceptive and antihyperalgesic properties. It is known to bind to presynaptic calcium channels involved in pain hypersensitivity andto indirectly inhibit NMDA receptor overactivation (17). This explains the drug's ability to limit long-term pain sensitization (18). Gabapentin and morphine have synergistic analgesic effects in animals and humans (19-21). In a recent study, a single dose of oral gabapentin reduced postoperative morphine consumption and pain after radical mastectomy (22). A small, retrospectivelymatched, case-controlled study showed a reduction in morphine requirement in acute burn patients following the administration of gabapentin for a 3-week period, commencing on day 3 after the burn (23).

\section{Objectives}

The aim of the present study was to determine the effect of a single preoperative oral dose of gabapentin on postprocedural and background pain and on PCA morphine consumption in burn patients after surgical resection of burn wounds.

\section{Patients and Methods}

After obtaining approval from the hospital ethical committee and obtaining written informed consent from all participants, 50 patients undergoing surgical debridement of burn wounds were enrolled in the study. Inclusion criteria were as follows: patients had to have 
an American Society of Anesthesiologists (ASA) physical status classification of I or II ( $\mathrm{I}=$ a normal healthy patient and II= a patient with mild systemic disease), had to be of age between 20 and 60 years, and had to have 10-35\% total body surface area (TBSA) burns in the lower limbs. Patients were not included if they could not operate a PCA device, were breast feeding, had an allergy to gabapentin or morphine, or had a history of alcohol or drug abuse, chronic pain, daily intake of analgesics or anticonvulsants, antidepressant use, diabetes, or impaired kidney function. The study was conducted using a double-blind randomized controlled design, and all the operations were performed by the same surgeon. All patients were informed, during the pre-anesthetic examination, aboutthe use of the PCA device and the visual analog scale (VAS), in which 0 (zero) $\mathrm{mm}$ represented no pain and $100 \mathrm{~mm}$ represented the worst pain imaginable. Patients were randomized, using a closed-envelope system, to receive either $1200 \mathrm{mg}$ oral gabapentin $(n=25)$ or placebo ( $n=25) 2 \mathrm{~h}$ before surgery. In the placebo group, patients were given placebo pills that were identical in appearance to gabapentin. Although the study drug (s) was given by a nurse, the investigators remained blinded to the group assignment. Upon arrival to the operating room, all patients were premedicated with $0.04 \mathrm{mg} / \mathrm{kg}$ of intravenous (IV) midazolam. Electrocardiographic electrodes and a non-invasive blood pressure monitor were applied and oxygen saturation $\left(\mathrm{SpO}_{2}\right)$ was monitored by pulse oximetry. Anesthesia was induced with $2 \mathrm{mg} / \mathrm{kg}$ propofol, $3 \mu \mathrm{g} / \mathrm{kg}$ fentanyl, and $0.5 \mathrm{mg} / \mathrm{kg}$ atracurium. After endotracheal intubation, anesthesia was maintained with propofol infusion at a rate of 50 to 150 $\mu \mathrm{g} / \mathrm{kg} / \mathrm{min}$ with a fixed infusion of $0.4 \mu \mathrm{g} / \mathrm{kg} / \mathrm{min}$ remifentanil, and $50 \% \mathrm{~N}_{2} \mathrm{O}$ in $\mathrm{O}_{2}$. The infusion of propofol and remifentanil was continued until the debridement of the burn wound was completed. Neuromuscular blockade was then reversed with IVadministration of $0.04 \mathrm{mg} / \mathrm{kg}$ neostigmine and $0.02 \mathrm{mg} / \mathrm{kg}$ atropine. After tracheal extubation, patients were transferred to the postanesthesia care unit (PACU). Postoperative analgesia was provided with IV-PCA morphine (2.5 mg bolus and 10 min lock-out time)upon arrival in the PACU. An additional $2.5 \mathrm{mg}$ of morphine was administered intravenously by a nurse observer, if requested by the patient during the lock-out period. During the first $1 \mathrm{~h}$ in the PACU, and then at 4, 8,12, 16,20 , and 24 hours after extubation, patients were evaluated for pain scores (VAS) at rest and during mobilization from the supine to the sitting position. total dose of morphine consumption, heart rate (HR), $\mathrm{SpO}_{2}$, mean arterial pressure (MAP), respiratory rate (RR), and sedation score were also evaluated by an anesthesiology resident not otherwise involved in the study. The occurrence of any side effects, such as nausea, vomiting, constipation, respiratory depression, dizziness, somnolence, diarrhea, headache, and pruritus, was recorded. Morphine was stopped if the patient had a $\mathrm{RR}<10$ breaths/min, $\mathrm{SpO}_{2}<$
$94 \%$ by pulse oximetry, or a serious adverse event related to opioid administration. Ondansetron ( $4 \mathrm{mg}$ ) was intravenously administered for nausea and vomiting upon patient request. No other medications were administered during the 24-h observation period. A sample size of 25 patients per group was calculated to detect a significant difference of $15 \%$ or more in morphine consumption with a power of $85 \%$ and a significance level of 5\%. Descriptive statistics are expressed as mean \pm standard deviation (SD) unless otherwise stated. Normality of distribution was tested by the Kolmogorov-Smirnovtest. Student's $t$-test was used for comparing the means of continuous variables and normally distributed data. The Mann-Whitney U-test was used in other cases. Two-way analysis of variance was used to compare groups, and Bonferroni correction and Tukey's honestly significant difference (HSD) test were used for multiple comparisons. Categorical data were analyzed using eitherthe $\chi^{2}$ testor Fisher's exact test, as appropriate. Significance was determined at $P<0.05$.

\section{Results}

From June1, 2009 to June 1, 2010, 50 consecutive patients who fulfilled the inclusion criteria were included in the study. All enrolled patients were able to complete the study; therefore, data from 50 patients were analyzed. The groups were comparable with respect to age, body weight, height, ASA physical status, duration of surgery, and burn size (Table 1). $\mathrm{MAP}, \mathrm{HR}, \mathrm{SpO}_{2}$, and respiratory rate were not different between the groups at any of the measured times (Table 2). Patients in the placebo group experienced more pain than the patients in the gabapentin group in both the lying and moving positions $(P<0.05)$ during the 24 -h period after the debridement procedure (Table 3$)$. Sedation scores were similar at all measured times in the gabapentin and placebo groups $(P>0.05)$. Postoperative morphine consumption at 8,12 , 16,20 , and $24 \mathrm{~h}$ after surgerywas significantly lower in the gabapentin group than in the placebo group $(P<0.05)$ (Table 4). Total morphine consumption was reduced from $52.45 \pm 10.4 \mathrm{mg}$ in the placebo group to $33.8 \pm 18 \mathrm{mg}$ in the gabapentin group $(P<0.05)$. The incidence of side effects is shown in Table 5. The most common side effects during the study were nausea and vomiting, but there was no difference in the incidence of side effects between the groups. Two patients in each group vomited, and 8 patients in the gabapentin group and 9 patients in the placebo group received ondansetron $(P>0.05)$.

\section{Discussion}

The main finding of this study was that a single, preoperative dose of $1200 \mathrm{mg}$ gabapentin decreased total postoperative morphine consumption and postoperative pain scores at rest and upon movement after debridement of burn wounds. Moreover, gabapentin was not 
Table 1. Demographic and Clinical Data of the Patients

\begin{tabular}{|c|c|c|}
\hline & Placebo $(n=25)^{b}$ & Gabapentin $(n=25)^{b}$ \\
\hline Age, $y$, Mean \pm SD $^{a}$ & $48.4 \pm 10.2$ & $50.5 \pm 11.2$ \\
\hline Weight, kg, Mean \pm SD ${ }^{\text {a }}$ & $70.5 \pm 12$ & $71.1 \pm 14.4$ \\
\hline \multicolumn{3}{|l|}{ Gender } \\
\hline Male & 8 & 7 \\
\hline Female & 17 & 18 \\
\hline \multicolumn{3}{|l|}{ ASA Physical status ${ }^{\text {a }}$} \\
\hline I & 20 & 21 \\
\hline II & 5 & 4 \\
\hline Duration of anesthesia, min, Mean $\pm \mathrm{SD}^{\mathrm{a}}$ & $23 \pm 67$ & $21 \pm 59$ \\
\hline Burn size, $\%$, Mean \pm SD $^{\text {a }}$ & $13 \pm 25$ & $19 \pm 29$ \\
\hline
\end{tabular}

${ }^{a}$ Abbreviations: ASA, American Society of Anesthesiologists; SD, Standard Deviation

${ }^{\mathrm{b}}$ No significant differences were found between the groups

\begin{tabular}{|c|c|c|}
\hline & Placebo $(n=25)^{b}$ & Gabapentin $(\mathbf{n}=25)^{b}$ \\
\hline \multicolumn{3}{|l|}{$0, \mathrm{~h}$} \\
\hline $\mathrm{HR}^{\mathrm{a}}$, beats/min, Mean $\pm \mathrm{SD}^{\mathrm{a}}$ & $99.2 \pm 18.3$ & $99.9 \pm 17.8$ \\
\hline $\mathrm{MAP}^{\mathrm{a}}, \mathrm{mm} \mathrm{Hg}$, Mean $\pm \mathrm{SD}$ & $113 \pm 22.1$ & $109.1 \pm 21.1$ \\
\hline $\mathrm{RR}^{\mathrm{a}}$, breaths/min, Mean $\pm \mathrm{SD}$ & $18.3 \pm 2$ & $17.4 \pm 1.9$ \\
\hline \multicolumn{3}{|l|}{$1, \mathrm{~h}$} \\
\hline HR, beats/min, Mean \pm SD & $97.6 \pm 17.9$ & $95.1 \pm 16.8$ \\
\hline MAP, mm Hg, Mean \pm SD & $106 \pm 21$ & $105 \pm 19.3$ \\
\hline RR, breaths/min, Mean \pm SD & $18.2 \pm 1.8$ & $18.1 \pm 1.5$ \\
\hline \multicolumn{3}{|l|}{$4, \mathrm{~h}$} \\
\hline HR, beats/min, Mean \pm SD & $95.1 \pm 4.2$ & $93.3 \pm 12.3$ \\
\hline MAP, mm Hg, Mean \pm SD & $102.1 \pm 11$ & $101.2 \pm 10.3$ \\
\hline $\mathrm{RR}$, breaths/min, Mean $\pm \mathrm{SD}$ & $19.2 \pm 1.5$ & $18.7 \pm 1.3$ \\
\hline \multicolumn{3}{|l|}{$8, \mathrm{~h}$} \\
\hline HR, beats/min, Mean \pm SD & $95.2 \pm 13.4$ & $89.2 \pm 13.2$ \\
\hline MAP, mm Hg, Mean \pm SD & $101 \pm 15.4$ & $100 \pm 14$ \\
\hline RR, breaths/min, Mean \pm SD & $17.7 \pm 1.2$ & $17.2 \pm 1.2$ \\
\hline \multicolumn{3}{|l|}{$12, \mathrm{~h}$} \\
\hline HR, beats/min, Mean \pm SD & $94 \pm 12.4$ & $89.4 \pm 13.3$ \\
\hline $\mathrm{MAP}, \mathrm{mm} \mathrm{Hg}$, mean $\pm \mathrm{SD}$ & $98.1 \pm 14.2$ & $95.4 \pm 14.6$ \\
\hline RR, breaths/min, Mean \pm SD & $17.1 \pm 1.2$ & $17.8 \pm 1.1$ \\
\hline \multicolumn{3}{|l|}{$16, \mathrm{~h}$} \\
\hline $\mathrm{HR}$, beats/min, Mean $\pm \mathrm{SD}$ & $90.1 \pm 13.2$ & $86.8 \pm 12.2$ \\
\hline MAP, mm Hg, Mean \pm SD & $95.0 \pm 12.4$ & $93.2 \pm 13.3$ \\
\hline $\mathrm{RR}$, breaths/min, Mean $\pm \mathrm{SD}$ & $16.4 \pm 1.1$ & $16.2 \pm 1.1$ \\
\hline \multicolumn{3}{|l|}{$20, \mathrm{~h}$} \\
\hline HR, beats/min, Mean \pm SD & $90.3 \pm 12.3$ & $88.2 \pm 11.1$ \\
\hline $\mathrm{MAP}, \mathrm{mm} \mathrm{Hg}$, Mean $\pm \mathrm{SD}$ & $90.4 \pm 12.2$ & $88.3 \pm 12.1$ \\
\hline $\mathrm{RR}$, breaths/min, Mean $\pm \mathrm{SD}$ & $16.5 \pm 1.5$ & $16.6 \pm 1.2$ \\
\hline \multicolumn{3}{|l|}{$24, \mathrm{~h}$} \\
\hline HR, beats/min, Mean \pm SD & $90.5 \pm 11.2$ & $88.9 \pm 10.5$ \\
\hline MAP, mm Hg, Mean \pm SD & $89 \pm 11.1$ & $87.1 \pm 10$ \\
\hline RR, breaths/min, Mean \pm SD & $15.2 \pm 1.0$ & $15.0 \pm 1.1$ \\
\hline
\end{tabular}

${ }^{a}$ Abbreviations: HR, Heart Rate; MAP, Mean Arterial Blood Pressure; RR, Respiratory Rate; SD, Standard Deviation

${ }^{\mathrm{b}}$ No significant differences were found between the groups 
Table 3. Postoperative Pain Scores in the Gabapentin and Placebo Groups

\begin{tabular}{|c|c|c|c|c|c|}
\hline \multicolumn{3}{|c|}{ Gabapentin $(n=25)$, Mean \pm SD } & \multicolumn{3}{|c|}{$\operatorname{Placebo}(n=25)$, Mean \pm SD } \\
\hline Variable & Sitting & Lying & Variable & Sitting & Lying \\
\hline $1 \mathrm{~h}$ & $35 \pm 28$ & $29 \pm 25^{a}$ & $1 \mathrm{~h}$ & $59 \pm 8$ & $54 \pm 14$ \\
\hline $4 \mathrm{~h}$ & $41 \pm 17^{\mathrm{a}}$ & $28 \pm 16^{a}$ & $4 \mathrm{~h}$ & $53 \pm 12$ & $52 \pm 10$ \\
\hline $8 \mathrm{~h}$ & $33 \pm 15^{a}$ & $19 \pm 9^{a}$ & $8 \mathrm{~h}$ & $50 \pm 12$ & $48 \pm 9$ \\
\hline $12 \mathrm{~h}$ & $30 \pm 12^{a}$ & $18 \pm 10^{\mathrm{a}}$ & $12 \mathrm{~h}$ & $50 \pm 12$ & $45 \pm 13$ \\
\hline $16 \mathrm{~h}$ & $23 \pm 9^{a}$ & $15 \pm 8^{a}$ & $16 \mathrm{~h}$ & $38 \pm 7$ & $38 \pm 10$ \\
\hline $20 \mathrm{~h}$ & $27 \pm 12^{\mathrm{a}}$ & $16 \pm 8^{a}$ & $20 \mathrm{~h}$ & $35 \pm 10$ & $33 \pm 10$ \\
\hline $24 \mathrm{~h}$ & $25 \pm 7^{\mathrm{a}}$ & $15 \pm 7^{\text {a }}$ & $24 \mathrm{~h}$ & $26 \pm 7$ & $26 \pm 12$ \\
\hline
\end{tabular}

a $P<0.05$, when compared with the placebo group

Table 4. Morphine Consumption in the Gabapentin and Placebo Groups

\begin{tabular}{lll}
\hline & Gabapentin $(\mathbf{n}=\mathbf{2 5})$, Mean \pm SD & Placebo $(\mathbf{n}=\mathbf{2 5})$, Mean \pm SD \\
\hline $1 \mathrm{~h}$ & $5.5 \pm 5.4$ & $7.4 \pm 2.7$ \\
$4 \mathrm{~h}$ & $3.9 \pm 3.2^{\mathrm{a}}$ & $8.2 \pm 2.9$ \\
$8 \mathrm{~h}$ & $2.8 \pm 3.1^{\mathrm{a}}$ & $8.1 \pm 2.4$ \\
$12 \mathrm{~h}$ & $2.6 \pm 2.2^{\mathrm{a}}$ & $9.2 \pm 2.1$ \\
$16 \mathrm{~h}$ & $3.43 \pm 3.8^{\mathrm{a}}$ & $7.15 \pm 1.7$ \\
$2 \mathrm{~h}$ & $2.9 \pm 3.3^{\mathrm{a}}$ & $6.2 \pm 2.4$ \\
$24 \mathrm{~h}$ & $1.2 \pm 0.6^{\mathrm{a}}$ & $3.5 \pm 0.5$ \\
Total & $33.8 \pm 18^{\mathrm{a}}$ & $52.45 \pm 10.4$ \\
\hline
\end{tabular}

a $P<0.05$, when compared with the placebo group

Table 5. Incidence of Side Effects in the Gabapentin and Placebo Groups

\begin{tabular}{lll}
\hline & Placebo $(\mathbf{n}=\mathbf{2 5})$ & Gabapentin $(\mathbf{n}=\mathbf{2 5})$ \\
\hline Dizziness & 1 & 2 \\
Nausea & 7 & 6 \\
Vomiting & 2 & 2 \\
Somnolence & 0 & 1 \\
Diarrhea & 2 & 0 \\
Pruritus & 2 & 0 \\
Urinary retention & 2 & 1 \\
Constipation & 2 & 2 \\
\hline
\end{tabular}

associated with more side effects than was the placebo. Coderre and Melzack confirmed that burn injuries not only make injured areas and surrounding tissues more painful but also cause hyperalgesia, which is a significant problem for many patients (24). In burn patients, hyperalgesia is further enhanced because the burn wounds heal slowly over days or weeks (11). Among pharmacological agents, morphine has continued to be the mainstay for both background and procedural pain management in burn patients. The long-term use of morphine has several inherent problems. Morphine binds to more than 1 receptor class, and morphine use is associated with side effects (respiratory depression, constipation, pruritus, and nausea) that limit tissue healing. An ad- ditional problem is the rapid development of tolerance to morphine and poor pain control in a small group of burn patients.Tolerance to morphine is associated with the activation of central glutamate pathways (NMDA receptors) and hyperalgesia. The main aim in combining different analgesic drugs is to obtain synergistic or additive analgesics that will allowthe administration of a smaller dose of each drug with an improved safety profile.This can be achieved by combining analgesics acting at different locations. Antihyperalgesic drugs like gabapentin may have a role in postoperative pain reduction, and their combination with other antinociceptive drugs may produce synergistic analgesic effects (25). Gabapentin is frequently used as a single preoperative oral dose for postoperative pain control in clinical studies. Single oral doses of gabapentin,as low as $600 \mathrm{mg}$ or $5 \mathrm{mg} / \mathrm{kg}$, have been shown to be effective in reducing postoperative pain (25). Gabapentin enhanced the analgesic effect of morphine in healthy volunteers (20), and the combination produced a better analgesic effect than morphine alone in patientswith neuropathic cancer pain (19). Gabapentin significantly decreased morphine consumption and pain in patients who underwent mastectomy (22). However, these patients were evaluated for only $4 \mathrm{~h}$ after surgery. In our study, we found a reduction in pain scores at rest and after movement throughout the 24 -h period, even though morphine consumption reduced only after 
the first 8h. In contrast, Fassoulaki et al. (26) were unable to demonstrate a decrease in analgesic consumption and VAS scores at rest or after movement during the first $24 \mathrm{~h}$ after the operation.Differences between the results of the 2 studies can be attributed to differences in the types of surgeries performed and the types of analgesics used. Nonsteroidalanti-inflammatory drugs (NSAIDs) are useful adjunctive analgesics for decreasing pain and opioid requirements in patients undergoing major surgery. However, their use in some groups of patients may be limited by adverse renal, gastrointestinal, and hemostatic effects. In contrast, gabapentin is well tolerated and has few side effects and only minor interactions with other drugs when used for the treatment of chronic pain (26-28). We did not observe any significant side effects associated with a single oral dose of gabapentin. In conclusion, by using gabapentin preemptively as an adjuvant to morphine-based postoperative analgesia, we aimed to obtain better postoperative pain profiles with fewer narcotic-related side effects. The present study shows that a single preoperativeoral dose of $1200 \mathrm{mg}$ gabapentin enhances the analgesic effect of morphine and decreases morphine consumption. However, further studies are necessary to determine the analgesic-sparing effect of different preoperative and postoperative doses of gabapentin for the management of burn pain.

\section{Acknowledgments}

The authors would like to thank the VUH Anesthesiology Research Center and the Nursing Department for their assistance with data collection.

\section{Financial Disclosure}

None declared.

\section{Funding/Support}

None declared.

\section{References}

1. Tracey I. Imaging pain. BrJ Anaesth. 2008;101(1):32-9.

2. Meyer RA, Campbell JN. Myelinated nociceptive afferents account for the hyperalgesia that follows a burn to the hand. Science.1981;213(4515):1527-9.

3. Andreasen NJ, Noyes R, Jr., Hartford CE ,Brodland G, Proctor S. Management of emotional reactions in seriously burned adults. N Engl J Med. 1972;286(2):65-9.

4. West DA, Shuck JM. Emotional problems of the severely burned patient. Surg Clin North Am. 1978;58(6):1189-204.

5. Choiniere M, MelzackR, Rondeau J, Girard N, Paquin MJ. The pain of burns: characteristics and correlates. JTrauma.1989;29(11):1531-9.

6. Atchison N, Guercio P, Monaco C. Pain in the pediatric burn patient: nursing assessment and perception. Issues Compr Pediatr
Nurs.1986;9(6):399-409

7. Edwards RR, Smith MT, Klick B, Magyar-Russell G, Haythornthwaite JA, Holavanahalli R, et al. Symptoms of depression and anxiety as unique predictors of pain-related outcomes following burn injury. Ann Behav Med. 2007;34(3):313-22.

8. Edwards RR, Magyar-Russell G, Thombs B, Smith MT, Holavanahalli RK, Patterson DR, et al. Acute pain at discharge from hospitalization is a prospective predictor of long-term suicidal ideation after burn injury. Arch Phys Med Rehabil. 2007;88(12 Suppl 2):S36-42.

9. Summer GJ, Puntillo KA, Miaskowski C, Green PG, Levine JD. Burn injury pain: the continuing challenge. J Pain. 2007;8(7):533-48.

10. Taal LA, Faber AW. Burn injuries, pain and distress: exploring the role of stress symptomatology. Burns.1997;23(4):288-90

11. Herndon DN. Total burn care. Saunders Elsevier; 2007.

12. Gaukroger PB, Chapman MJ, Davey RB. Pain control in paediatric burns--the use of patient-controlled analgesia. Burns. 1991;17(5):396-9.

13. Kinsella J, Glavin R, Reid WH. Patient-controlled analgesia for burn patients: a preliminary report. Burns Incl Therm Inj. 1988;14(6):500-3.

14. Guignard B, Bossard AE, Coste C, Sessler DI, Lebrault C, Alfonsi $\mathrm{P}$, et al. Acute opioid tolerance: intraoperative remifentanil increases postoperative pain and morphine requirement. Anesthesiology. 2000;93(2):409-17.

15. Kissin I, Bright CA, Bradley EL, Jr. The effect of ketamine on opioid-induced acute tolerance: can it explain reduction of opioid consumption with ketamine-opioid analgesic combinations? Anesth Analg. 2000;91(6):1483-8.

16. Benzon HT. Essentials of pain medicine and regional anesthesia. Elsevier-Churchill Livingstone; 2005.

17. Simonnet G. Preemptive antihyperalgesia to improve preemptive analgesia. Anesthesiology. 2008;108(3):352-4.

18. Van Elstraete AC, Sitbon P, Mazoit JX, Benhamou D. Gabapentin prevents delayed and long-lasting hyperalgesia induced by fentanyl in rats. Anesthesiology. 2008;108(3):484-94.

19. Caraceni A, Zecca E, Martini C, De Conno F. Gabapentin as an adjuvant to opioid analgesia for neuropathic cancer pain. J Pain Symptom Manage. 1999;17(6):441-5.

20. Eckhardt K, Ammon S, Hofmann U, Riebe A, Gugeler N, Mikus G. Gabapentin enhances the analgesic effect of morphine in healthy volunteers. Anesth Analg. 2000;91(1):185-91.

21. Shimoyama M, Shimoyama N, Inturrisi CE, Elliott KJ. Gabapentin enhances the antinociceptive effects of spinal morphine in the rat tail-flick test. Pain.1997;72(3):375-82.

22. Dirks J, Fredensborg BB, Christensen D, Fomsgaard JS, Flyger H, Dahl JB. Arandomized study of the effects of single-dose gabapentin versus placebo on postoperative pain and morphine consumption after mastectomy. Anesthesiology. 2002;97(3):560-4.

23. Cuignet O, Pirson J, Soudon O, Zizi M. Effects of gabapentin on morphine consumption and pain in severely burned patients. Burns. 2007;33(1):81-6.

24. Coderre TJ, Melzack R. Increased pain sensitivity following heat injury involves a central mechanism. Behav Brain Res. 1985;15(3):259-62.

25. Seib RK, Paul JE. Preoperative gabapentin for postoperative analgesia: a meta-analysis. Can J Anaesth. 2006;53(5):461-9.

26. Fassoulaki A, Patris K, Sarantopoulos C, Hogan Q. The analgesic effect of gabapentin and mexiletine after breast surgery for cancer. Anesth Analg. 2002;95(4):985-91, table of contents.

27. Mao J, Chen LL. Gabapentin in pain management. Anesth Analg. 2000;91(3):680-7.

28. McLean MJ, Morrell MJ, Willmore LJ, Privitera MD, Faught RE, Holmes GL, et al. Safety and tolerability of gabapentin as adjunctive therapy in a large, multicenter study. Epilepsia. 1999;40(7):965-72. 